\title{
CHARACTERIZATION STUDY OF POLYCRYSTALLINE TIN OXIDE
}

SURFACES BEFORE AND AFTER REDUCTION IN CO

\author{
Jean E. Drawdy, Gar B. Hoflund and Mark R. Davidson \\ Department of Chemical Engineering \\ University of Florida \\ Gainesville, Florida
}

David R. Schryer

NASA Langley Research Center

Hampton, Virginia

\begin{abstract}
Polycrystalline tin oxide surfaces have been examined before and after reduction in 40 Torr of $\mathrm{CO}$ at 100 and $175^{\circ} \mathrm{C}$ using Auger electron spectroscopy (AES), electron spectroscopy for chemical analysis (ESCA), ion scattering spectroscopy (ISS) and electron stimulated desorption (ESD). The changes in the surface composition and chemical states of the surface species generally are subtle for the reductive conditions used. However, significant changes do occur with regard to the amounts and the chemical forms of the hydrogen-containing species remaining after both the 100 and $175^{\circ} \mathrm{C}$ reductions.
\end{abstract}

\section{INTRODUCTION}

Tin oxide is an important component in many catalytic systems including $\mathrm{Pt} / \mathrm{SnO}_{\mathrm{x}}$ for low-temperature $\mathrm{CO}$ oxidation $(1-4)$, electrocatalytic methanol oxidation (5-8) and oxygen reduction (9-11); $\mathrm{CrO}_{\mathrm{x}} / \mathrm{SnO}_{\mathrm{y}}$ (12) and $\mathrm{SnO}_{\mathrm{x}} / \mathrm{CuO}$ (13) for NOX reduction; $\mathrm{SbO}_{\mathrm{x}} / \mathrm{SnO}_{\mathrm{y}}(14)$ and $\mathrm{CuO}_{\mathrm{x}} / \mathrm{SnO}_{\mathrm{y}}(15)$ for selective oxidation of propene to acrolein; and $\mathrm{Pt} / \mathrm{Sn} / \mathrm{Al}_{2} \mathrm{O}_{3}$ for hydrocarbon reforming (16-20). Most tin oxide-containing catalysts are activated by pretreating in $\mathrm{CO}$ or $\mathrm{H}_{2}$ at elevated temperature prior to use as a catalyst. The conditions used during the reductive pretreatment are very important in optimizing the activity of a given catalyst. This is expected since tin oxide is a hydrated, reducible oxide. During reduction of tin oxide several changes occur including loss of water of hydration, loss of surface hydroxyl groups and loss of lattice oxygen to form Sno, suboxides or tin metal. All of these processes can occur, and the extent of each process depends upon the severity of the reductive treatment. Therefore, a large variety of complex surfaces can be produced by varying the parameters of the reductive process. This has a large effect on the catalytic properties of the surface particularly since the surface hydrogen content and the REDOX behavior of reduced tin oxide are often responsible for its catalytic properties in numerous reactions.

Previous studies (21-25) have shown that hydrogen is a major constituent of tin oxide surfaces. Nevertheless, many commonly used surface techniques are relatively insensitive to surface hydrogen so it often is neglected even though it may be responsible for the chemical behavior of a given tin oxide surface. It is of interest to determine both the chemical forms of the hydrogen present and their concentrations which is quite difficult. Tarlov and Evans (25) have addressed this topic using X-ray photoelectron spectroscopy (XPS or ESCA) and suggest that various complex forms of mixed tin oxides and 
hydroxides and adsorbed water exist on tin oxide surfaces depending upon the history of a given surface. Electron stimulated desorption (ESD) (23) is another surface technique which is particularly useful for examining surface hydrogen present at tin oxide surfaces (21). ESD yields information about the relative amounts of hydrogen present at various surfaces and is capable of distinguishing between different chemical forms. Unfortunately, it is difficult to determine the nature of the adsorbed forms of surface hydrogen from the ESD spectral features.

A few studies of the reduction of tin oxide by annealing in vacuum $(21,22,24-29)$ or a reducing gas at low pressure (30), by ion bombardment (2629,31 ) or by exposure to a reducing plasma (32) have appeared, but the reduction of tin oxide in a reducing gas at higher pressure and elevated temperature apparently has not been addressed. The purpose of this present study is to examine the changes induced at a polycrystalline tin oxide surface by reduction in 40 Torr of $\mathrm{CO}$ at 100 and $175^{\circ} \mathrm{C}$ for 1 hour. These conditions are similar to those often used to activate tin oxide-containing catalysts. Furthrmore, ESD is used in these studies to examine hydrogen present at these surfaces before and after reduction. The next part of this study describes the effects of reduction on platinized tin oxide films and compares their behavior with that of bare tin oxide films presented in this study.

\section{EXPER IMENTAL}

Thin polycrystalline tin oxide films supported on titania foil were prepared using a high temperature spray hydrolysis method described previously (33). These films were analyzed before and after reduction in 40 Torr of $c 0$ at 100 and $175^{\circ} \mathrm{C}$ for 1 hour. The reduction was carried out in a sample pretreatment chamber attached to the ultrahigh vacuum analysis chambers (base pressure of $10^{-11}$ Torr) using a sample heater system (34) which does not dissociate the reducing gas.

The tin oxide films were analyzed before and after reduction using several surface characterization techniques including Auger electron spectroscopy (AES), ion scattering spectroscopy (ISS), ESCA and ESD. AES, ISS and ESCA were performed using a double-pass cylindrical mirror analyzer (CMA) (PerkinElmer PHI Model 25-270) as the charged-particle energy analyzer. AES was performed using the internal, coaxial electron gun with a primary beam energy of $3 \mathrm{keV}$, spot size of about $0.5 \mathrm{~mm}$ and primary beam current of about $10 \mathrm{uA}$. The CMA was operated in the nonretarding mode using phase-sensitive detection with a $10 \mathrm{kHz}$ oscillating voltage of $0.5 \mathrm{Vpp}$ applied to the outer cylinder. ISS was also performed in the nonretarding mode using pulse counting detection (35). A $1 \mathrm{keV}{ }^{4} \mathrm{He}^{+}$primary ion beam (100 nA defocused over a spot size of about $1 \mathrm{~cm}$ in diameter) was used. Exposure to the primary beams in both AES and ISS was minimized in order to reduce beam-induced damage. ESCA was performed using $\mathrm{Mg} \mathrm{Ka}$ excitation and operating the CMA in the retarding mode with a $50 \mathrm{eV}$ pass energy for collection of survey spectra and a $25 \mathrm{eV}$ pass energy for collection of high-resolution spectra.

ESD was performed using a quadrupole mass spectrometer coupled to an energy prefilter and ion focldsing lens (23) as the ion detection system. A $2 \mathrm{keV}, 100 \mathrm{nA}$ primary electron beam defocused over a spot of $1.0 \mathrm{~mm}$ diameter provided the excitation. Two types of ESD spectra were collected. The first was a mass spectrum obtained by collecting ions of kinetic energy between 2 
and $3 \mathrm{eV}$. The second was an ion energy distribution (ESDIED) at selected masses.

\section{RESULTS AND DISCUSSION}

\section{A. ISS, AES and ESCA Results}

Three sets of ISS, AES, ESCA and ESD data were taken from an as-prepared tin oxide sample, a sample reduced at $100^{\circ} \mathrm{C}$ and a sample reduced at $175^{\circ} \mathrm{C}$ both in 40 Torr of $\mathrm{CO}$ for 1 hour. These data are described and compared in this section. An ESCA survey spectrum taken from the tin oxide film reduced at $100^{\circ} \mathrm{C}$ is shown in figure 1 . This spectrum exhibits peaks due to 0 and $\mathrm{Sn}$ but no peak due to $C$. It is similar to the ESCA survey spectra taken from the asprepared sample and the sample reduced at $175^{\circ} \mathrm{C}$ except that the $0 / \mathrm{Sn}$ ratio varies from sample to sample. Also, the 0 and $S n$ peak shapes obtained from the three samples vary as described below.

Auger spectra taken from the as-prepared, $100^{\circ} \mathrm{C}$-reduced and $175^{\circ} \mathrm{C}$-reduced samples are shown in figures 2,3 and 4 respectively. Although the spectra appear to be quite similar, there are substantial differences. Peaks due only to $\mathrm{Sn}$ and 0 appear in these spectra except for the spectrum taken from the $100^{\circ} \mathrm{C}$-reduced sample which also exhibits a fairly large $\mathrm{C}$ peak considering the fact that the $C$ AES sensitivity factor is smaller than that of $S n$ and 0 (36). Other differences include the shapes of the predominant $S n$ and $O$ peaks, the low kinetic-energy structure and the $\mathrm{O} / \mathrm{Sn}$ peak-height ratios. The asprepared sample exhibits both $\mathrm{Sn}$ and $\mathrm{O}$ peaks and low-energy features which differ considerably from the equivalent features in the spectra obtained from the reduced samples. The Sn Auger peak positions of the metal and oxide differ by about $5 \mathrm{eV}$ so a mixture of $\mathrm{Sn}$ metal and oxides produce a feature with a reduced splitting between the two peaks compared to either the metallic or oxidic feature as discussed in previous studies $(3,37,38)$. Thus, the shape of the predominant tin peaks in figure 2 indicates that the surface of the asprepared sample consists of a mixture of metallic tin and tin oxide. Both the $0 / \mathrm{Sn}$ peak-height ratio and the shape of the low kinetic energy features (50-90 $\mathrm{eV}$ ) are consistent with this suggestion. Based on UPS data and work function measurements, Powell and Spicer (39) first suggested that the outermost layer of $S n$ remains metallic during oxidation. This is supported by an ISS, ESCA and AES study by Asbury and Hoflund (37) in which they showed that 0 penetrates beneath the $\mathrm{Sn}$ surface during oxidation leaving a layer of $\mathrm{Sn}$ at the surface. An angle-resolved ESCA study by Asbury and Hoflund (40)* showed that the near-surface region of the oxygen-exposed sample is enriched in $\mathrm{Sn}$ and that this $\mathrm{Sn}$ is metallic. Although much evidence collected in different studies over many years suggests that the outermost layer of a tin oxide surface consists of metallic $\mathrm{Sn}$, this notion is contrary to intuitive thinking. Therefore, continued effort should be devoted to gaining more direct evidence related to this interesting question.

The Auger spectra taken from the samples reduced at 100 and $175^{\circ} \mathrm{C}$ in $\mathrm{CO}$ shown in figures 3 and 4 respectively contain $S n$ features which have increased splitting compared to that in figure 2 , and these peaks are shifted to slightly higher kinetic energies. Also, the low kinetic energy features have decreased considerably. These changes are indicative of oxidation of the metallic component of the as-prepared sample. It seems unusual that a reductive treatment would result in more complete oxidation of the outermost atomic *Unpublished data 
layer. However, the same phenomenon has been observed in a surface characterization study of $\mathrm{TiO}_{2}(001)$ (41). In this study it was shown that sputtering a $\mathrm{TiO}_{2}(001)$ surface lowers the 0 concentration in the near-surface region by creating $O$ vacancies. Annealing this surface in $10^{-6}$ Torr of $\mathrm{H}_{2}$ at $400^{\circ} \mathrm{C}$ actually increases the 0 concentration in the near-surface region by providing a chemical driving potential which results in the migration of bulk 0 to the surface. It appears that a similar process occurs by annealing an as-prepared tin oxide surface in $C O$ resulting in oxidation of the metallic $S n$ overlayer and the concommitant changes in the Auger spectral features.

ISS spectra taken from the as-prepared, $100^{\circ} \mathrm{C}$-reduced and $175^{\circ} \mathrm{C}$-reduced tin oxide surfaces are shown in figure $5 a, b$ and $c$ respectively. ISS is an important surface analytical technique because it is highly surface sensitive yielding compositional information about the outermost atomic layer whereas AES and ESCA probe much more deeply beneath the surface. The ISS spectrum shown in figure $5 a$ exhibits three features; a large $S n$ peak at an $E / E_{O}$ of 0.87 , a very small $O$ peak at an $E / E_{O}$ of 0.37 and an even smaller $C l$ peak at an $E / E_{O}$ of 0.65 . A peak due to $C$ at an $E / E_{O}$ of 0.28 does not appear in this spectrum. This spectrum is characteristic of those obtained from polycrystalline $\mathrm{Sn}$ exposed to $\mathrm{O}_{2}$ at lower pressure or to air (37). Furthermore, the inelastic background is very low, which is characteristic of ion scattering from a metallic surface (42). This fact lends support to the assertion that the outermost atomic layer of an as-prepared tin oxide surface is metallic $\mathrm{Sn}$.

An ISS spectrum taken from the $100^{\circ} \mathrm{C}$-reduced tin oxide surface is shown in figure 5b. The 0 peak is comparable to that shown in figure $5 a$ obtained from the as-prepared surface. However, a broad and poorly defined peak appears at an $E / E_{O}$ lower than that of $O$ (about 0.26 ). This feature is due to $C$; an assignment which is consistent with the fact that a significant $C$ peak appears in the Auger spectrum obtained from this surface (see figure 3 ). There are two possible reasons for the presence of this $C$. The first reason is $C$ contamination, but this probably is not the source since the other tin oxide surfaces do not exhibit any features due to $C$. The second and more likely possibility is that 0 vacancies are produced at or just beneath the surface through removal of lattice 0 to form $\mathrm{CO}_{2}$ during the reduction. These vacancies may be active sites for adsorption of Co molecules thereby resulting in the presence of $\mathrm{C}$ at this surface. Also, the AES O/Sn ratio is greater for this surface than for the as-prepared surface. This fact supports the assertion that adsorbed CO probably is the source of $\mathrm{C}$ on the $100^{\circ} \mathrm{C}$-reduced surface.

The ISS spectrum taken from the $175^{\circ} \mathrm{C}$-reduced tin oxide surface is shown in figure 5c. This spectrum exhibits only two peaks due to $\mathrm{Sn}$ and $\mathrm{O}$, and the 0 peak is smaller than those obtained from the as-prepared and $100^{\circ} \mathrm{C}-$ reduced surfaces. No peak due to $\mathrm{Cl}$ is present. The background is quite low indicating that the surface is conductive. This agrees with the results of electrical conductivity studies $(43,44)$ which show that tin oxide surfaces exhibit much lower resistivity after reduction.

The ESCA Sn $3 d_{5 / 2}$ peaks obtained from the as-prepared and $100^{\circ}$-reduced samples are shown in figure 6. The differences are fairly small so it is difficult to draw conclusions concerning the chemical changes which occur during the reduction from these spectra. The spectrum obtained from the reduced sample has a FWHM which is about $0.2 \mathrm{eV}$ wider than that of the spec- 
trum obtained from the as-prepared sample. Paparazzo et al. (45) have examined $\mathrm{SnO}$ and $\mathrm{SnO}_{2}$ standards and claim that there is a $0.18 \mathrm{eV}$ difference in Sn 3d binding energy. Therefore, the increase in FWHM during reduction probably is due to conversion of $\mathrm{Sn}^{+4}$ to $\mathrm{Sn}^{+2}$. Although ESCA is fairly insensitive for distinguishing between $\mathrm{Sn}^{+4}$ and $\mathrm{Sn}^{+2}$, electron energy loss spectroscopy (ELS) is capable of making this distinction (31). Studies using ELS are currently in progress to monitor the $\mathrm{Sn}$ chemical state during the reduction of tin oxide.

The metallic $\mathrm{Sn} 3 \mathrm{~d}_{5 / 2}$ ESCA peak lies at about $484.6 \mathrm{eV}$ which is about 1.8 $\mathrm{eV}$ lower than the binding energy of the $\mathrm{SnO}_{2} \mathrm{Sn} 3 \mathrm{~d}_{5 / 2}$ ESCA peak. Clearly, a significant metallic $S n$ peak is not present before the reduction nor does one form during reduction. ESCA probes quite deeply beneath the surface ( 60 A) compared to AES and particularly compared to ISS. This fact suggests that the absence of a distinct metallic $S n$ peak in the ESCA $S n 3 d_{5 / 2}$ spectrum obtained from the as-prepared sample does not imply that an atomic layer of metallic $\mathrm{Sn}$ is not present at the surface. In fact, preliminary angle-resolved ESCA data (40) do indicate that the surface layer of air-exposed polycrystalline $\mathrm{Sn}$ is metallic. Although a distinct metallic $\mathrm{Sn} 3 \mathrm{~d}_{5 / 2}$ peak does not appear in figure 6 , the increase in the ESCA signal near $484.6 \mathrm{eV}$ may be due to the formation of a small amount of metallic Sn during the $100^{\circ} \mathrm{C}$ reduction.

The ESCA 0 is peaks taken from the as-prepared, $100^{\circ} \mathrm{C}$-reduced and $175^{\circ} \mathrm{C}-$ reduced tin oxide surfaces are shown in figure $7 a$ and $b$.

There are several forms of 0 at these surfaces including adsorbed water, hydroxyl groups bond to both $\mathrm{Sn}^{+2}$ and $\mathrm{Sn}^{+4}, \mathrm{SnO}^{+2} \mathrm{SnO}_{2}$ and possibly multiple forms of adsorbed oxygen (46). Although numerous ESCA studies of tin oxide have been published, very little reliable information, e.g., binding energies and peak shape data, is available due to the difficulty in interpreting the complex 0 and Sn ESCA features. Generally, the primary oxidic 0 is ESCA feature due to $\mathrm{Sno}$ or $\mathrm{SnO}_{2}$ has a binding energy of $530.6 \mathrm{eV}$, that due to hydroxyl groups has a binding energy of $531.8 \mathrm{eV}$ and the peak due to adsorbed water has a binding energy of $532.8 \mathrm{eV}$ (25). Considering the high resolution data presented in figure 7 , it is apparent that changes in the chemical states of the 0 species present in about the outermost 50-60 \& do occur during these reductions and that these changes are both complex and subtle. It is interesting that the $01 \mathrm{~s}$ peak shape obtained from the as-prepared sample is similar to that obtained from the $175^{\circ} \mathrm{C}$-reduced surface. One important difference is that the spectrum taken from the as-prepared surface exhibits more structure on the high binding energy side which is due to adsorbed water and hydroxyl groups. A secondary ion mass spectrometry (SIMS) study (22) has shown that these species mostly reside in a hydrated layer about 30 \& thick at these tin oxide surfaces. The concentrations of these species are reduced by the reduction at $175^{\circ} \mathrm{C}$. The $100^{\circ} \mathrm{C}$-reduced surface yields 0 is peak with a lower binding energy of about $530.3 \mathrm{eV}$ and an increased FWHM. The Auger spectrum obtained from this surface has an $0 / S n$ ratio which is greater than that of the as-prepared and $175^{\circ} \mathrm{C}$-reduced surfaces. This additional 0 may be due to adsorbed $\mathrm{CO}$, other 0-containing species which do not desorb or decompose at $100^{\circ} \mathrm{C}$ and subsurface 0 which migrates to the surface under a chemical driving potential provided by the reducing environment. These same species also are probably responsible for the increased FWHM of the $01 \mathrm{~s}$ spectrum in $f$ igure $7 \mathrm{~b}$.

The as-prepared and $175^{\circ} \mathrm{C}$-reduced samples do not yield a $\mathrm{C}$ is ESCA peak, but the $100^{\circ} \mathrm{C}$-reduced surface does as shown in figure 8 . This feature appears 
to be composed of at least four different peaks with binding energies of $284.5,285.6,287.3$ and $288.5 \mathrm{eV}$. Some of these peaks are due to contamination which accumulated during sample preparation or atmospheric exposure, and one or more of these features may be due to $\mathrm{CO}$ which adsorbed during the $100^{\circ} \mathrm{C}$ reduction.

\section{B. ESD Results}

Two different types of ESD spectra were taken in this study. The first is mass $(\mathrm{m} / \mathrm{e})$ spectra obtained by mass analyzing electron-stimulated desorbing ions at a preselected kinetic energy. The second is ion-energy distribution (ESDIED) spectra obtaining by preselecting mass and scanning some energy range (typically $0-10$ or $0-20 \mathrm{eV}$ ).

An m/e ESD spectrum obtained from the as-prepared sample is shown in figure 9. Peaks due to $\mathrm{H}^{+}(1 \mathrm{amu}), \mathrm{H}_{2}^{+}(2 \mathrm{amu}), \mathrm{O}^{+}(16 \mathrm{amu}), \mathrm{OH}^{+}(17 \mathrm{amu}), \mathrm{H}_{2} \mathrm{O}^{+}(18$ amu $), \mathrm{H}_{3} \mathrm{O}^{+}(19 \mathrm{amu}), \mathrm{CO}^{+}$or $\mathrm{N}_{2}^{+}(28 \mathrm{amu})$, and $\mathrm{Cl}^{+}(35$ and $37 \mathrm{amu})$ are observed in this spectrum. There are considerable variations in the peak heights in this spectrum, but since the ESD cross sections are not known and can vary considerably, it is not currently possible to determine species surface concentrations from these spectra. The $\mathrm{H}^{+}$peak is the largest (peaks of higher mass have been expanded by a factor of 3 ), and the $\mathrm{H}_{3} \mathrm{O}^{+}$peak height is about onethird that of the $\mathrm{H}^{+}$peak. All other peaks are quite small compared to the $\mathrm{H}^{+}$ peak. The various peaks containing $H$ and $O$ are expected since these elements are both major constituents of these tin oxide films. The $\mathrm{Cl}$ is also a constituent present in small quantities since $\mathrm{SnCl}_{4}$ and $\mathrm{HCl}$ are components used to prepare the tin oxide films. The $\mathrm{CO}$ or $\mathrm{N}_{2}$ peak is due to contamination and has been observed in previous ESD studies of tin oxide films (47). ESD is a very sensitive technique both with regard to composition and to depth specificity (23). Comparison of the ESD spectrum in figure 9 with those of previous studies (47) shows that the tin oxide films examined in this study contain very low levels of surface contamination. Both $\mathrm{H}_{3} \mathrm{O}^{+}$and $\mathrm{F}^{+}$species could comprise the 19 amu ESD peak. Surface studies of F-containing surfaces (48)* indicate that when an $\mathrm{F}^{+}$peak is present in ESD spectra, an $F$ peak also appears in the corresponding Auger spectra. Since no $F$ peak is present in the Auger spectra obtained from these tin oxide surfaces, the 19 amu ESD peak is assigned as due to $\mathrm{H}_{3} \mathrm{O}^{+}$in this study.

ESDIED spectra for the 1,2,16,17,18 and 19 amu species are shown in figure $10 a, b, c, d, e$ and $f$ respectively. Important information can be gained from these spectra because each surface species desorbs with a characteristic kinetic energy distribution assuming that multiple desorption mechanisms are not operative (23). This method has been used by Corallo and Hoflund (49) to show that multiple states of adsorbed $\mathrm{H}$ are present on an annealed Si(100) surface. In that study it is shown that very small features in the ESDIED spectra are reproducible and meaningful. This fact is important with regard to the interpretation of the tin oxide ESDIED spectra presented below. The 1 amu spectrum clearly consists of multiple features with kinetic energies 0.7 , $1.2,2.1,2.7,3.1,4.7,5.4,7.5$ and $10 \mathrm{eV}$. Other $\mathrm{H}$ binding states may be present, but they do not yield readily distinguishable features. Although ESDIED is usually capable of identifying and distinguishing between different binding states, it does not yield specific bonding information about these states. In this sense ESDIED is similar to temperature programmed desorption (TPD). The $\mathrm{H}_{2}^{+}$ESDIED spectrum consists of a narrow and well-defined ESDIED

*Unpublished data 
peak with a kinetic energy of $1.4 \mathrm{eV}$ and higher lying peaks at about 6 and 17 eV with a gently increasing background indicative of a broad distribution of binding states which desorb with large kinetic energies. Both the 16 and 17 amu ESDIED spectra are similar in shape exhibiting peaks due to four bonding states at $1.2,2.0,2.7$ and $3.7 \mathrm{ev}$. This may suggest that they are physically related. Perhaps a desorbing $\mathrm{OH}^{+}$splits into a neutral $\mathrm{H}$ and $\mathrm{O}^{+}$which then has the same ESDIED spectrum as the $\mathrm{OH}^{+}$. The 16 amu ESDIED spectrum also exhibits peaks at $4.7,7$ and $18 \mathrm{eV}$. The main feature in the $\mathrm{H}_{2} \mathrm{O}^{+}$ESDIED spectrum is fairly broad and may be composed of two peaks with kinetic energies of 1.4 and $2.5 \mathrm{eV}$. Since the $\mathrm{H}_{2}$ peak also has a kinetic energy of 1.4 $\mathrm{eV}$, it is possible that the origin ${ }^{2}$ of the detected $\mathrm{H}_{2}^{+}$species is through decomposition of a desorbing $\mathrm{H}_{2} \mathrm{O}^{+}$into a neutral 0 and $\mathrm{H}_{2}^{+}$. This is more plausible than the existence of molecularly adsorbed $\mathrm{H}_{2}$ which then desorbs as $\mathrm{H}_{2}^{+}$. A shoulder also appears at $3.6 \mathrm{eV}$ on the 18 amu ESDIED spectrum which is $a^{2}$ third binding state of adsorbed $\mathrm{H}_{2} \mathrm{O}$, and an increasing background due to binding states which yield higher kinetic energy ions is also present. The $\mathrm{H}_{3} \mathrm{O}^{+}$ESDIED spectrum consists of multiple peaks with kinetic energies of 0.7 , $1.2,3.1,3.6,4.0,5.0$ and $7.5 \mathrm{eV}$. The $19 \mathrm{amu}$ peak is quite large. This is reasonable since an adsorbed $\mathrm{H}_{2} \mathrm{O}$ probably would readily pick up an $\mathrm{H}^{+}$in the $\mathrm{H}-\mathrm{rich}$ environment of this surface. It is apparent from these complex ESD data that numerous $\mathrm{O}_{\mathrm{x}} \mathrm{H}_{\mathrm{y}}$ species are present in varying amounts on tin oxide surfaces. Although most previous studies of tin oxide surfaces discuss hydroxyl groups and adsorbed water and make assignments based on the presence of these species, such specific assignments appear to be dubious based on these ESD results.

An m/e and the corresponding ESDIED spectra taken from the $100^{\circ} \mathrm{C}$-reduced tin oxide surface are shown in figures 11 and 12 respectively. The ESD signals are all smaller after the reductive treatment indicating the loss of hydrogen-containing species during the reduction. The $\mathrm{Cl}^{+}$peaks are no longer present in the $\mathrm{m} / \mathrm{e}$ spectrum, and small 14 and 28 amu peaks appear. The $14 \mathrm{amu}$ peak is due to $\mathrm{N}^{+}$and has been observed previously (47). Also, the $\mathrm{H}_{3} \mathrm{O}^{+} / \mathrm{H}^{+}$ peak-height ratio is decreased by the reduction.

The 1 amu ESDIED spectrum shown in figure 12 has a considerably different shape than that obtained from the as-prepared sample and also contains many features. However, it is difficult to make a direct comparison with $\mathrm{H}^{+}$ESDIED spectrum shown in figure 10 because the spectra obtained from the $100^{\circ} \mathrm{C}$ reduced surface are shifted to lower kinetic energies. The magnitude of this shift is about $1.4 \mathrm{eV}$, but its origin is not understood. The 19 amu spectrum has a similar shape before and after the $100^{\circ} \mathrm{C}$ reduction, but the 17 amu peak is considerably narrower. This suggests the loss of one or more forms of hydroxyl groups during the reduction.

$\mathrm{m} / \mathrm{e}$ ESD and ESDIED spectra taken from the $175^{\circ} \mathrm{C}$-reduced sample are shown in figures 13 and 14 respectively. Peaks due to $\mathrm{H}^{+}, \mathrm{H}_{2}^{+}, \mathrm{OH}^{+}, \mathrm{H}_{2} \mathrm{O}^{+}, \mathrm{H}_{3} \mathrm{O}^{+}$and $\mathrm{CO}^{+}$appear in the m/e spectrum, but the signal strength is low indicating that even more hydrogen-containing species are removed during the $175^{\circ} \mathrm{C}$ reduction. It is interesting to note that both the 19 and 2 peaks are of significant size and that the size of the $\mathrm{H}_{2}^{+}$peak is nearly as large as the $\mathrm{H}_{3} \mathrm{O}^{+}$ peak. It is possible that most of the adsorbed water was removed during the $175^{\circ} \mathrm{C}$ reduction but that the chemical form which remains yields the desorbing $\mathrm{H}_{2}^{+}$species. 
It was only possible to obtain ESDIED spectra for the $\mathrm{H}^{+}$and $\mathrm{H}_{3} \mathrm{O}^{+}$desorbing ions because the signal strengths were too low for the other desorbing ions. The spectra shown in figure 14 also have shifted in kinetic energy but about $1 \mathrm{eV}$ to higher kinetic energy in this case. Again, the spectral shape varies significantly indicating that the types of hydrogen-containing species at the surface are further altered by the $175^{\circ} \mathrm{C}$ reduction. 


\section{REFERENCES}

1. Closed-Cycle, Frequency-Stable $\mathrm{CO}_{2}$ Laser Technology, proceedings of a workshop sponsored by NASA Langley Research Center, Hampton, Virginia, June $10-12,1986$, NASA Conference Publication $2456,1987$.

2. D.S. Stark, A. Crocker and G.J. Steward, J. Phys. E: Sci. Instrum. $16(1983) 158$.

3. J.E. Drawdy, G.B. Hoflund, S.D. Gardner, E. Yngvadottir and D.R. Schryer, Surface Interface Anal. 00(1990)00.

4. D.R. Schryer, B.T. Upchurch, J.D. Van Norman, K.G. Brown and J. Schryer, J. Catal. 00(1990)00.

5. M.M.P. Janssen and J. Moolhuysen, J. Catal. 46(1977)289.

6. M.M.P. Janssen and J. Moolhuysen, Electrochim. Acta $21(1976) 869$.

7. M.R. Andrew, J.S. Drury, B.D. McNicol, C. Pinnington and R.T. Short, J. Appl. Electrochem. ó(1976)99.

8. A. Katayama, J. Phys. Chem. 84(1980)376.

9. M. Watanabe, S. Venkatesan and H.A. Laitinen, J. Electrochem. Soc. $130(1983) 59$.

10. C. Iwakura, M. Ina1, T. Uemura and $\mathrm{H}$. Tamura, Electrochim. Acta $26(1981) 579$.

11. A.C.C. Tseung and S.C. Dhara, Electrochim. Acta 19(1974)845.

12. F. Solymosi and J. Kiss, J. Catal. 54(1978)42.

13. M.J. Fuller and M.E. Warwick, J. Catal. 42(1976)418.

14. Y. Boudeville, F. Figueras, M. Forissier, J.-L. Portefaix and J.C. Vedrine, J. Catal. 58(1979)52.

15. D.E. Self, J.E. Drawdy (Oakes) and M.G. White, AIChE J. 29(1983)625.

16. R. Burch and L.C. Garla, J. Catal. 71(1981)360.

17. F.M. Dautzenberg, J.N. Helle, P. Biloen and W.M.H. Sachtler, J. Catal. $63(1980) 119$.

18. B. Coq and F. Figueras, J. Mol. Catal. 25(1984)87.

19. J. Volter, G. Lietz, M. Uhlemann and M. Hermann, J. Catal. 68(1981)42.

20. G.B. Hoflund, D.A. Asbury and R.E. Gilbert, Thin Solid Films $129(1985) 139$. 
21. G.B. Hoflund, A.L. Grogan, Jr., D.A. Asbury and D.R. Schryer, Thin Solid Films 169(1989)69.

22. D.F. Cox, G.B. Hoflund and W.H. Hocking, Appl. Surface Sci. $26 ́(1986) 239$.

23. G.B. Hoflund, Scanning Electron Microscopy IV (1985)1391.

24. D.F. Cox, G.B. Hoflund and H.A. Laitinen, Appl. Surface Sci. $20(1984) 30$.

25. M.J. Tarlov and J.F. Evans, Chem. Mater. 00(1990)00.

26. D.F. Cox, T.B. Fryberger and S. Semancik, Phys. Rev. B 38(1988)2072.

27. E. de Fresart, J. Darville and J.M. Gilles, Solid State Commun. $37(1980) 13$.

28. E. de Fresart, J. Darville and J.M. Gilles, Appl. Surface Sci. $11 / 12(1982) 637$.

29. E. de Fresart, J. Darville and J.M. Gilles, Surface Sci. 126(1983)518.

30. T.W. Capenart and S.C. Chang, J. Vac. Sci. Technol. 18(1981)393.

31. D.F. Cox and G.B. Hoflund, Surface Sci. 151(1985)202.

32. J.H. Thomas III, Appl. Phys. Lett. 42(1983)794.

33. G.B. Hoflund, D.F. Cox, G.L. Woodson and H.A. Laitinen, Thin Solid Films $78(1981) 357$.

34. G.B. Hoflund, M.R. Davidson and G.R. Corallo, to be published.

35. R.E. Gilbert, D.F. Cox and G.B. Hoflund, Rev. Sci. Instrum. $53(1982) 1281$.

36. L.E. Davis, N.C. MacDonald, P.W. Palmberg, G.E. Riach and R.E. Weber, Handbook of Auger Electron Spectroscopy, Physical Electronics Division, Perkin-Elmer Corporation, Eden Prairie, Minnesota, 1976.

37. D.A. Asbury and G.B. Hoflund, J. Vac. Sci. Technol. A 5(1987)1132.

38. D.A. Asbury and G.B. Hoflund, Surface Sci. 199(1988)552.

39. R.A. Powell and W.E. Spicer, Surface Sci. 55(1976)681.

40. D.A. Asbury and G.B. Hoflund

41. G.B. Hoflund, H.-L. Yin, A.L. Grogan, Jr., D.A. Asbury, H. Yoneyama, 0. Ikeda and H. Tamura, Langmuir $4(1988) 346$.

42. S.D. Gardner, G.B. Hoflund, M.R. Davidson and D.R. Schryer, J. Cata. $115(1989) 132$. 
43. T.W. Capehart and S.-C. Chang, J. Vac. Sci. Technol. 18(1981)393.

44. S. -C. Chang, J. Vac. Sci. Technol. A 1(1983)524.

45. E. Paparazzo, G. Fierro, G.M. Ingo and N. Zacchetti, Surface Inter. Anal . 12(1988) 438 .

46. S.-C. Chang, J. Vac. Sci. Technol. 17(1980) 366.

47. G.B. Hoflund, D.F. Cox, F. Ohuchi, P.H. Holloway and H.A. Laitinen, Appl. Surface Sci. 14(1982-83)281.

48. M.R. Davidson and G.B. Hoflund

49. C.R. Corallo and G.B. Hoflund, Surface Inter. Anal. 12(1988)297. 


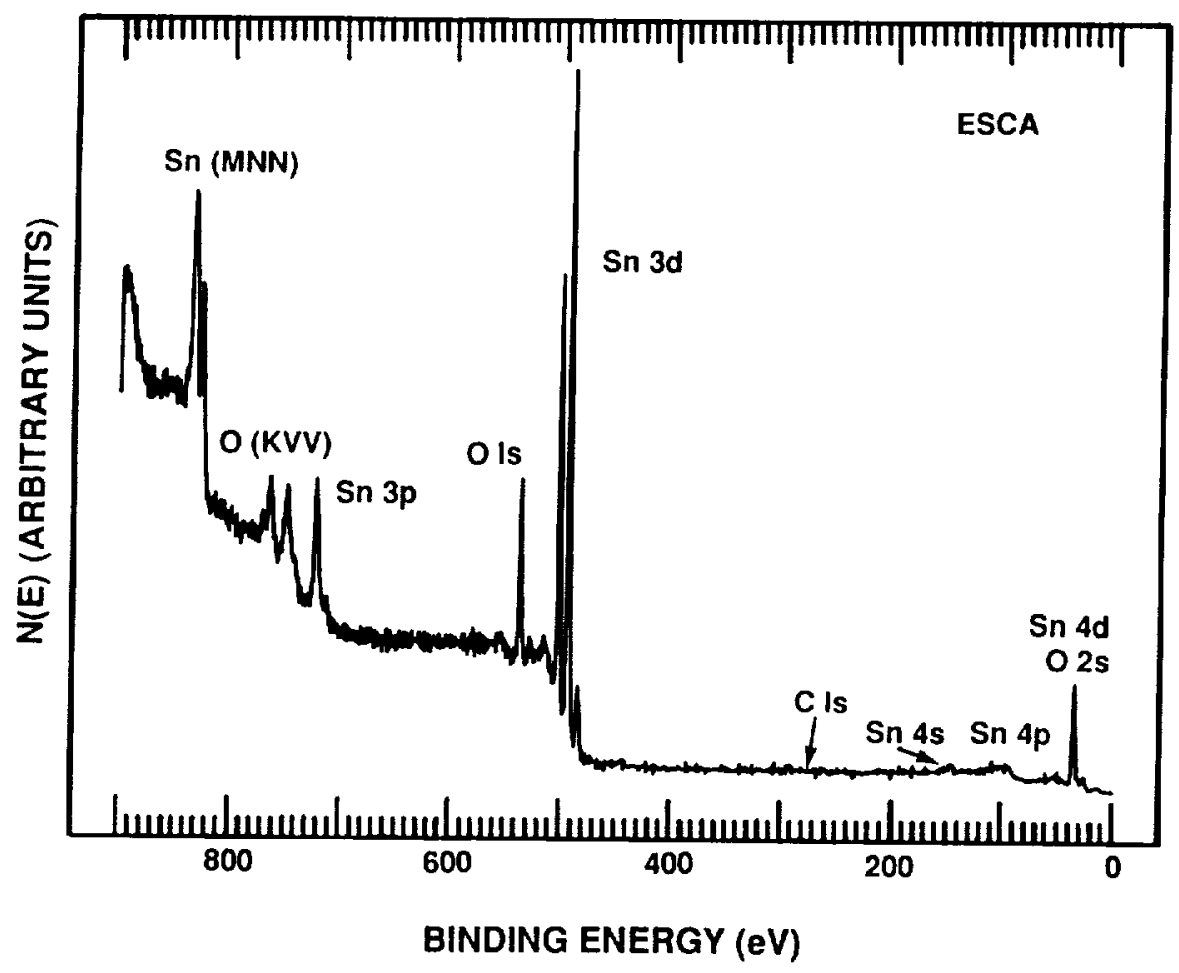

Figure 1. Survey ESCA spectrum taken from the $100^{\circ} \mathrm{C}$-reduced tin oxide sample.

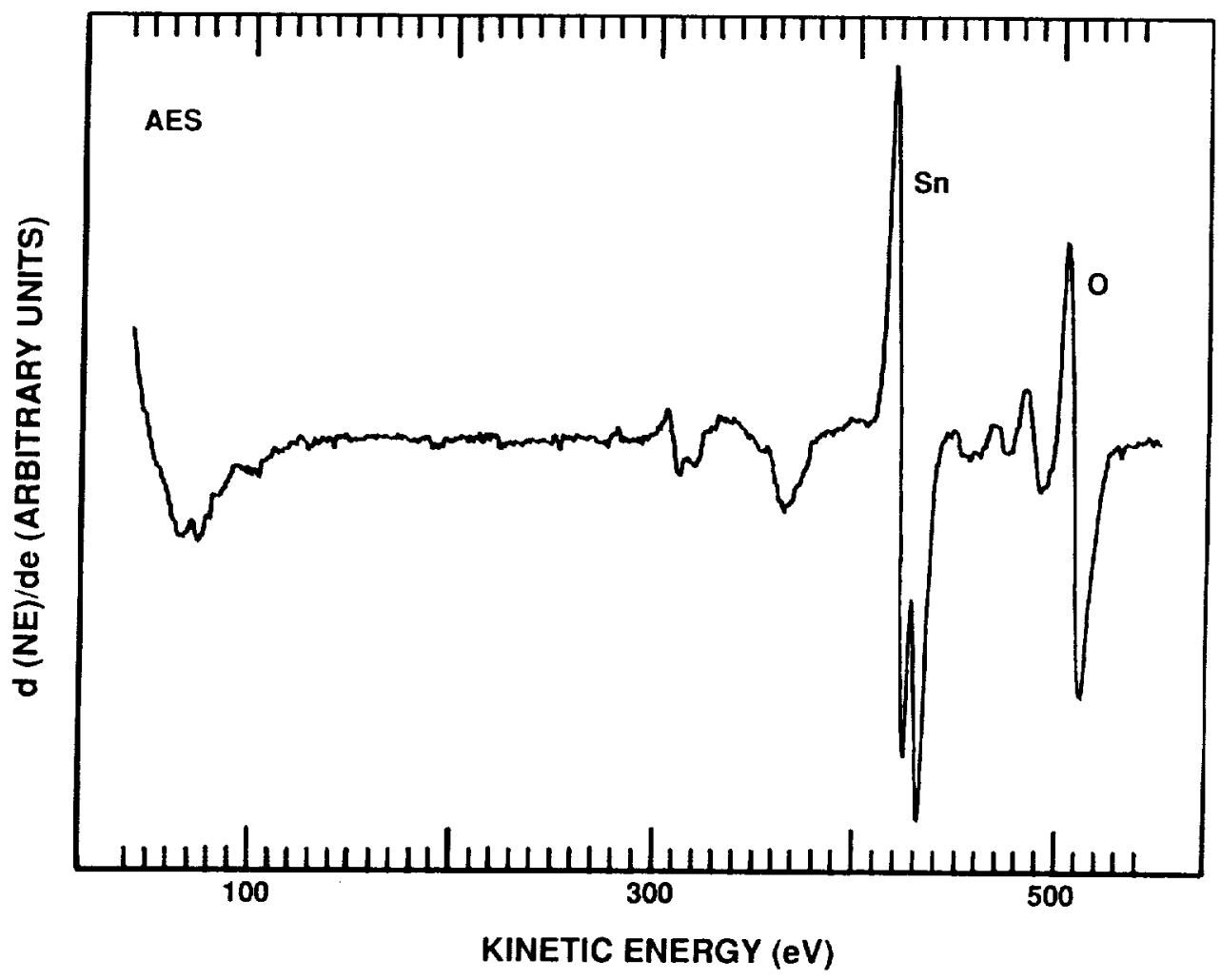

Figure 2. Auger spectrum taken from the as-prepared tin oxide sample. 


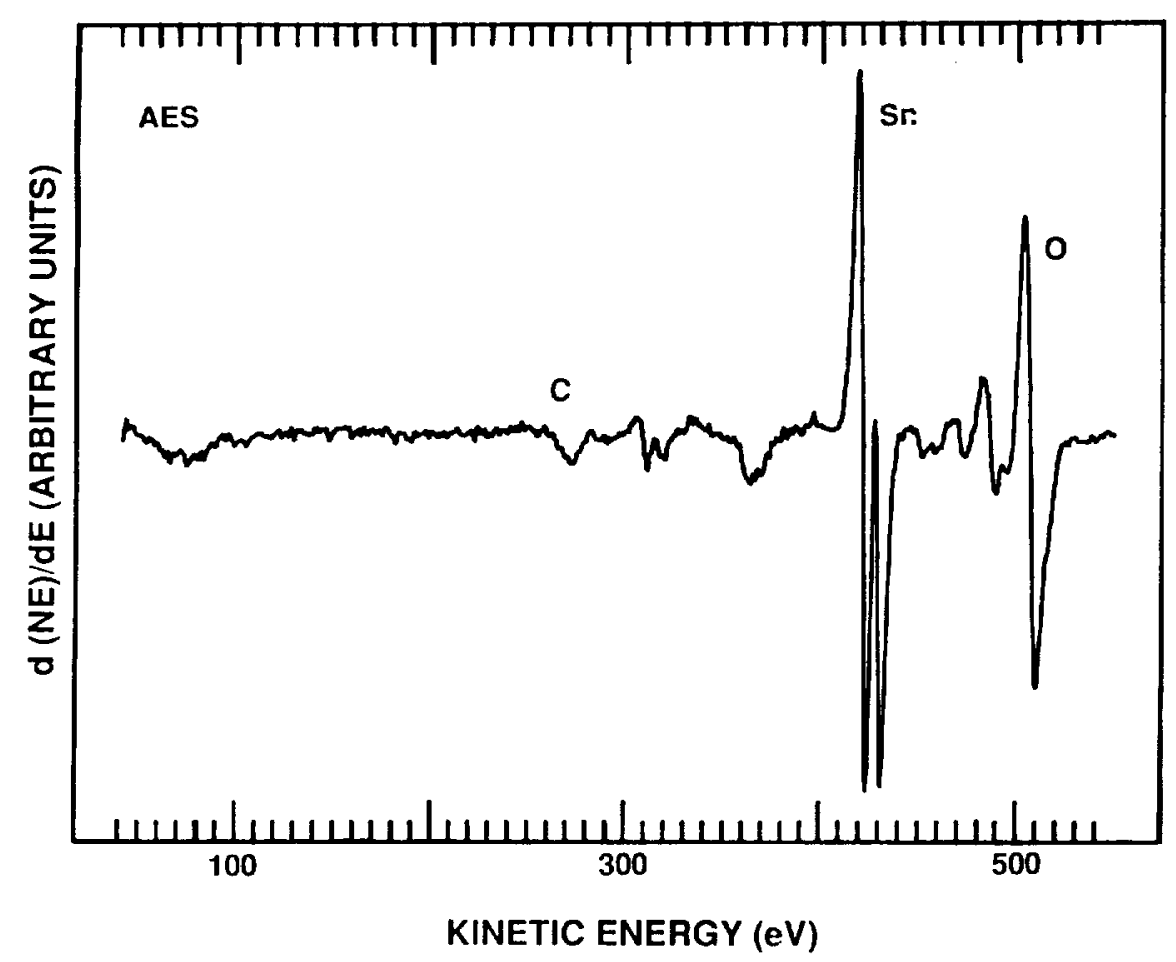

Figure 3. Auger spectrum taken from the $100^{\circ} \mathrm{C}$-reduced tin oxide sample.

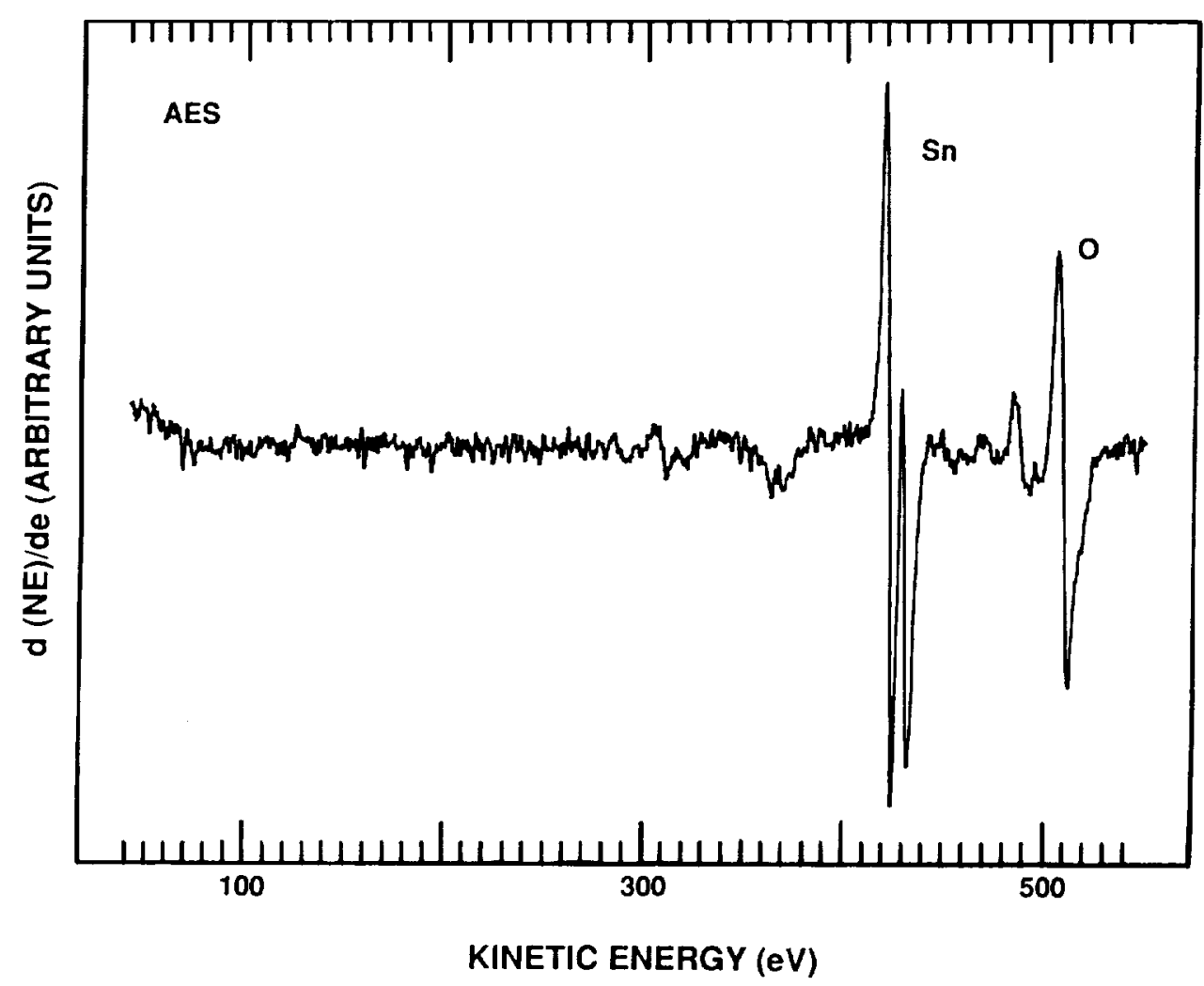

Figure 4. Auger spectrum taken from the $175^{\circ} \mathrm{C}$-reduced tin oxide sample. 


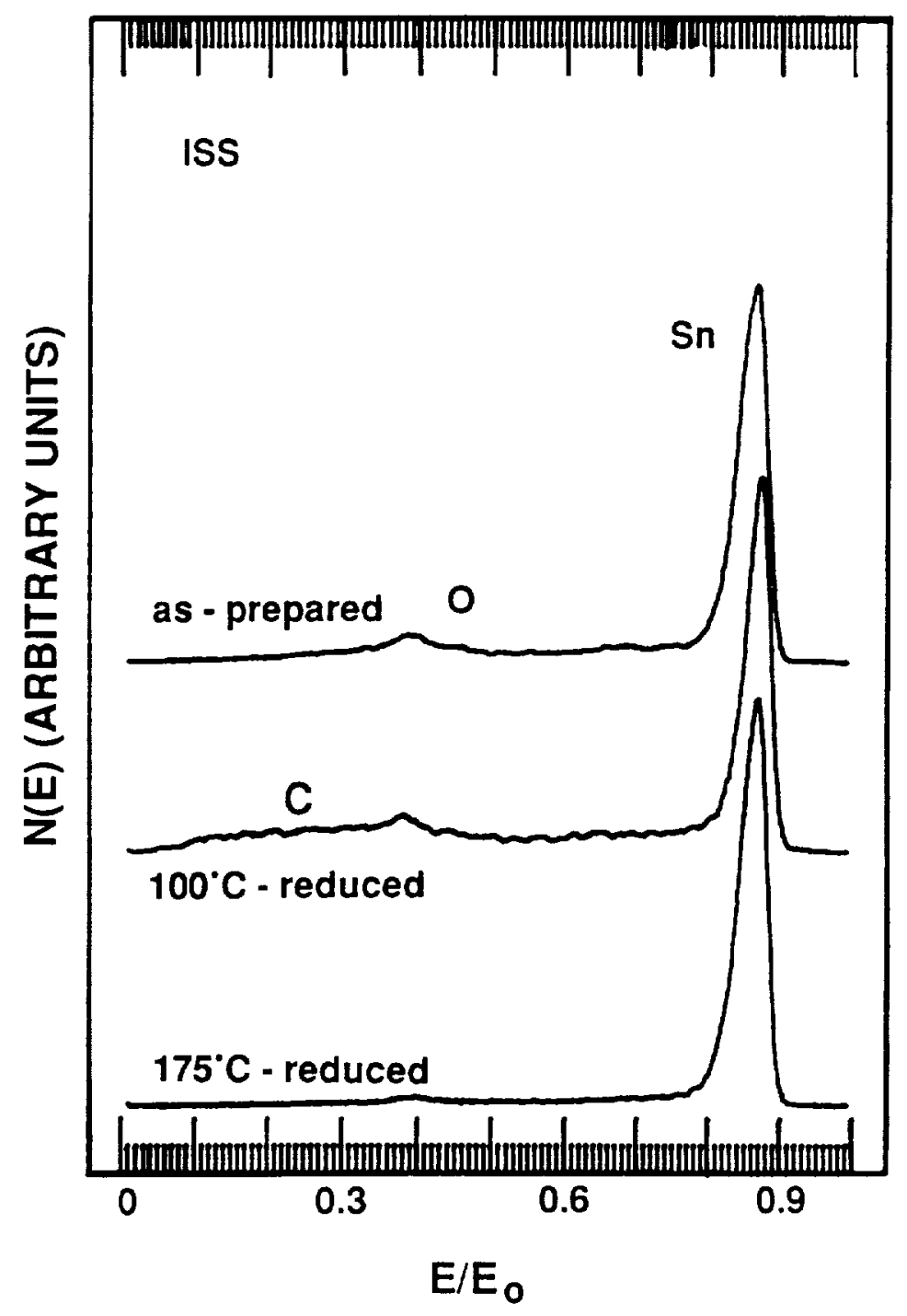

Figure 5. ISS spectra obtained from (a) an as-prepared tin oxide surface, (b) a tin oxide reduced at $100^{\circ} \mathrm{C}$ in $\mathrm{CO}$, and (c) a tin oxide surface reduced at $175^{\circ} \mathrm{C}$ in $\mathrm{CO}$. 


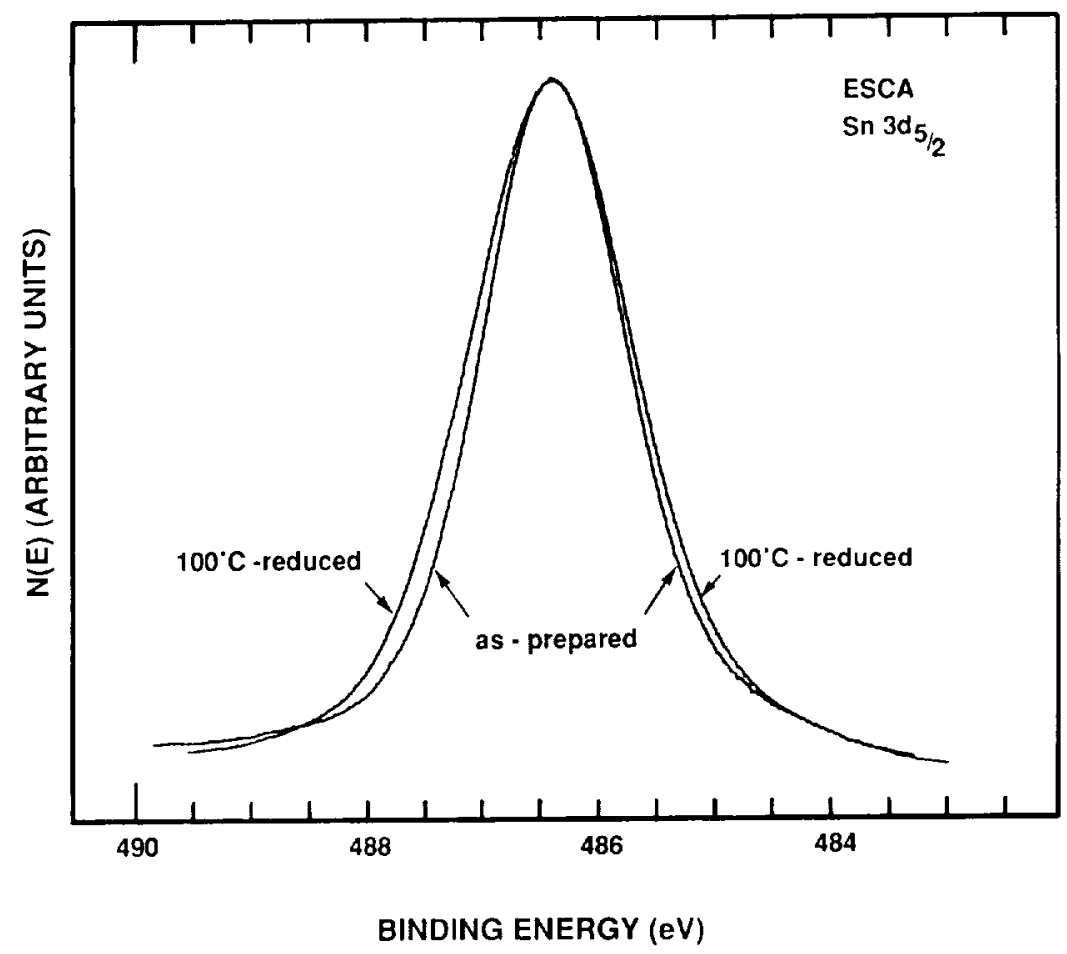

Figure 6. Sn $3 \mathrm{~d}_{5 / 2}$ spectra taken from the as-prepared and $100^{\circ} \mathrm{C}$-reduced tin oxide surfaces. 


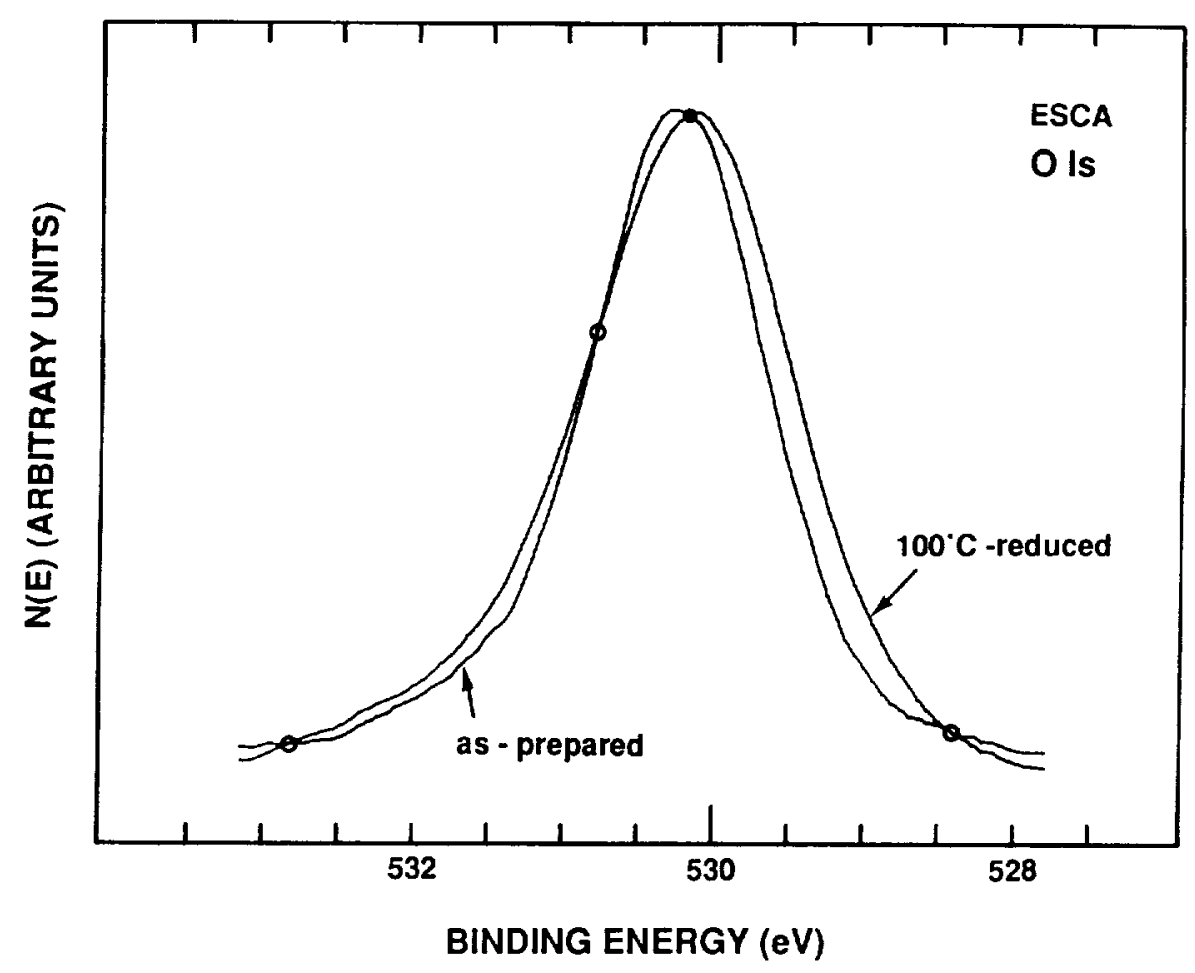

a

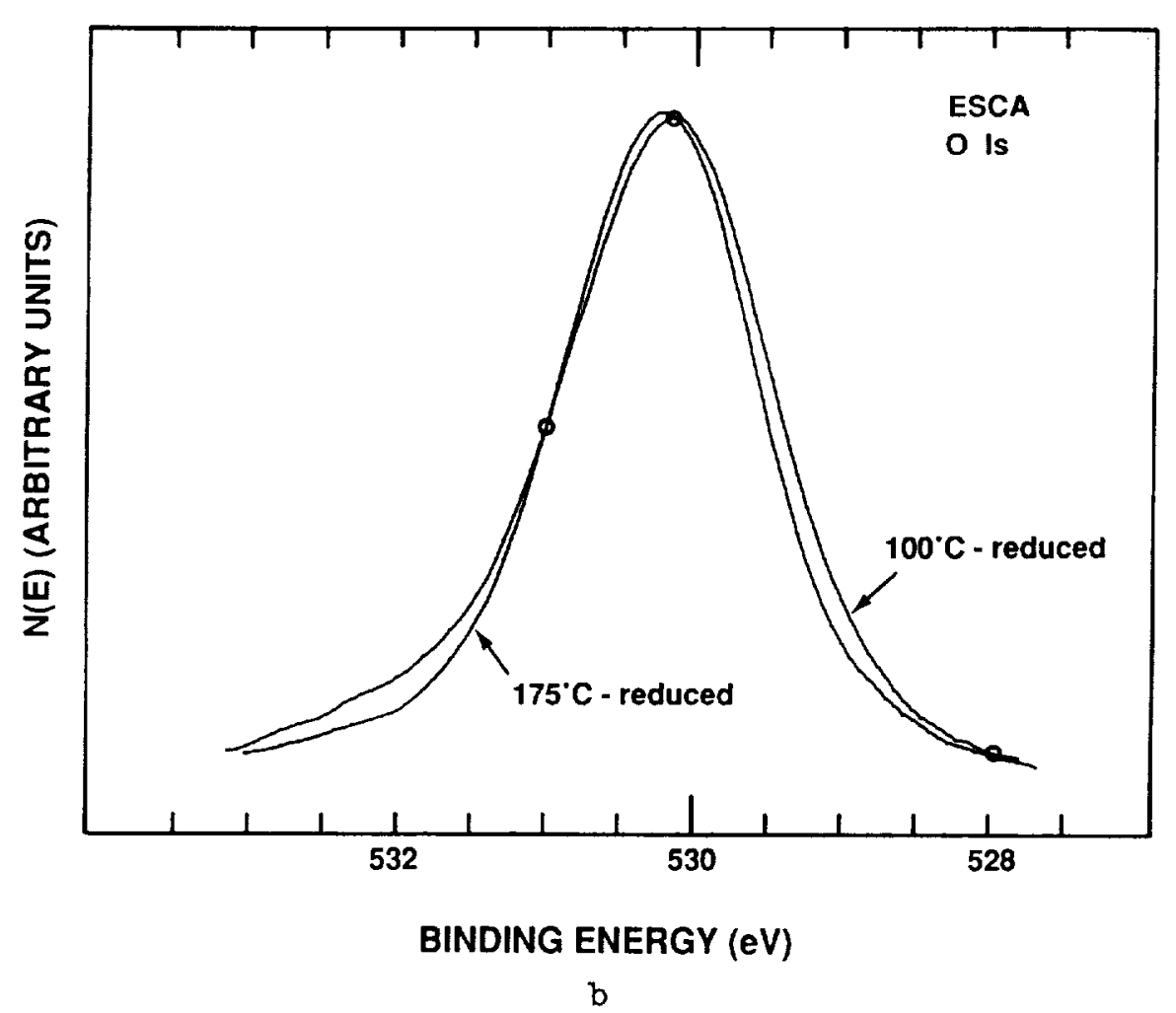

Figure 7. $01 \mathrm{~s}$ spectra taken from the as-prepared, $100^{\circ} \mathrm{C}$-reduced and $175^{\circ} \mathrm{C}-$ reduced tin oxide surfaces. 


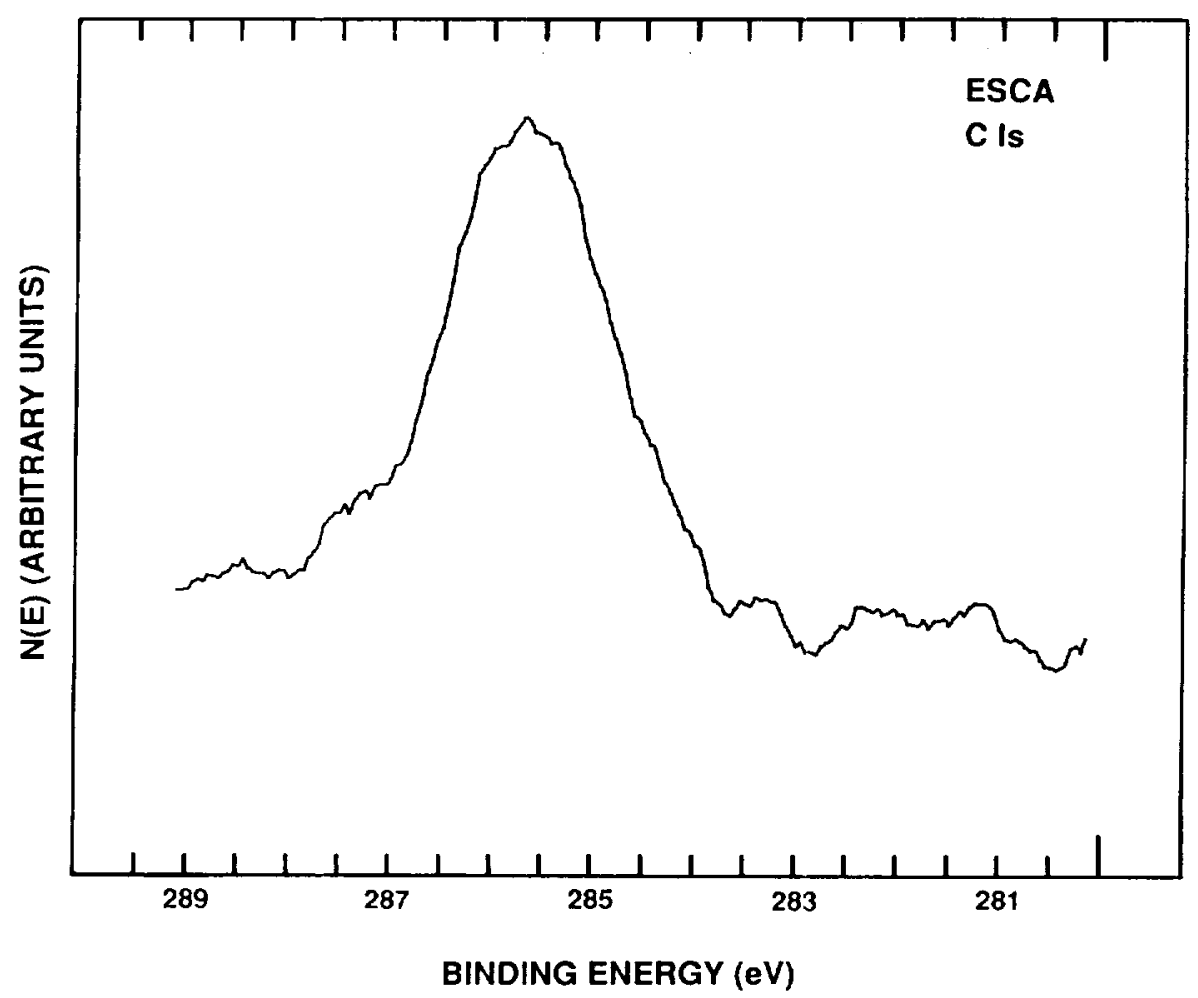

Figure 8. C is spectrum taken from the $100^{\circ} \mathrm{C}$-reduced tin oxide surface.

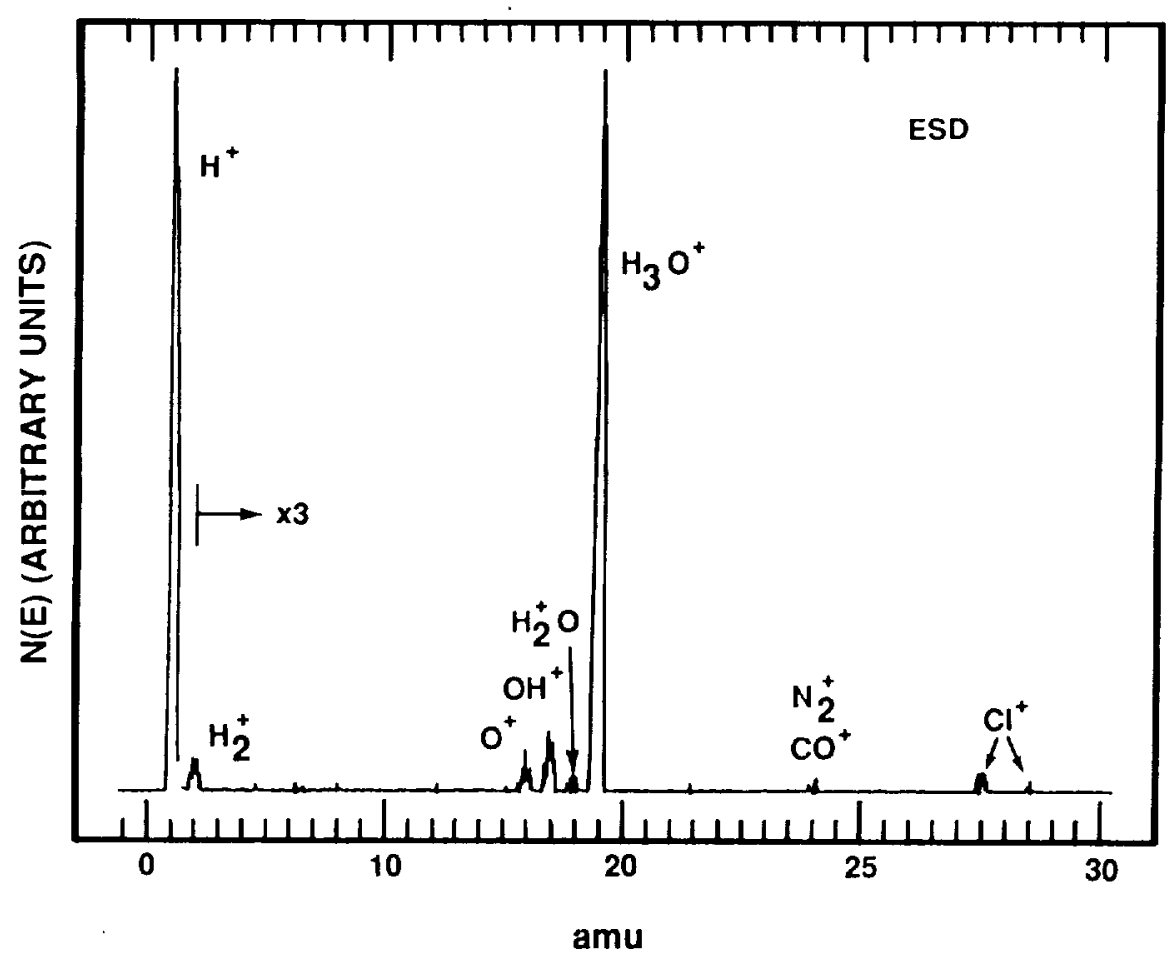

Figure 9. $m / e$ ESD spectrum taken from the as-prepared tin oxide surface. 


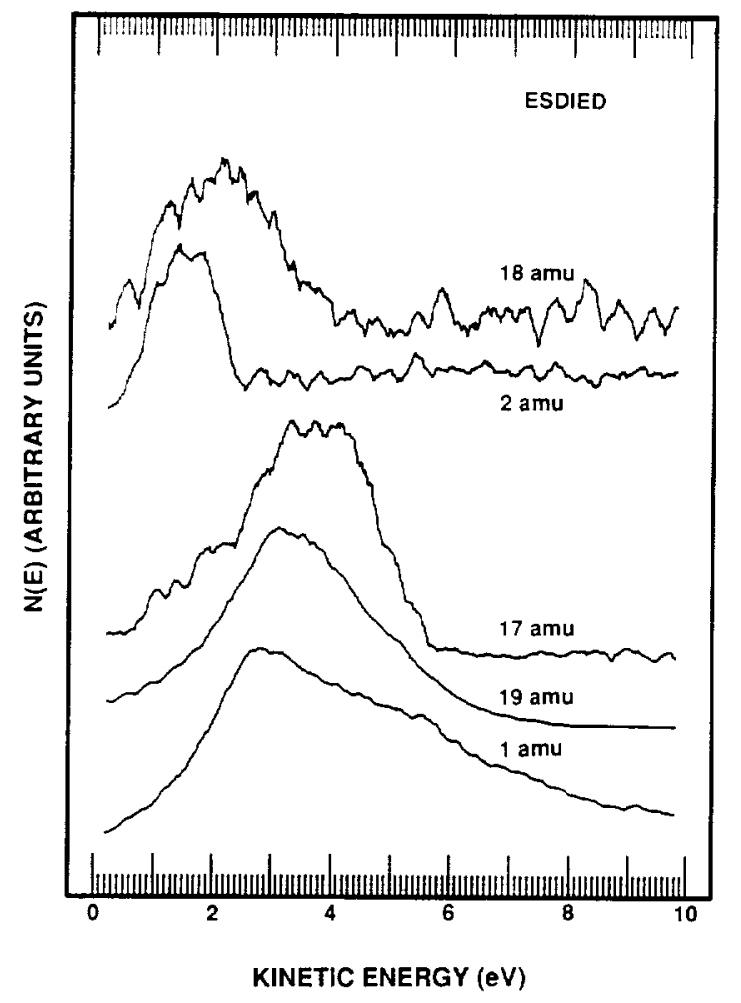

Figure 10. ESDIED spectra taken from the as-prepared tin oxide sample.

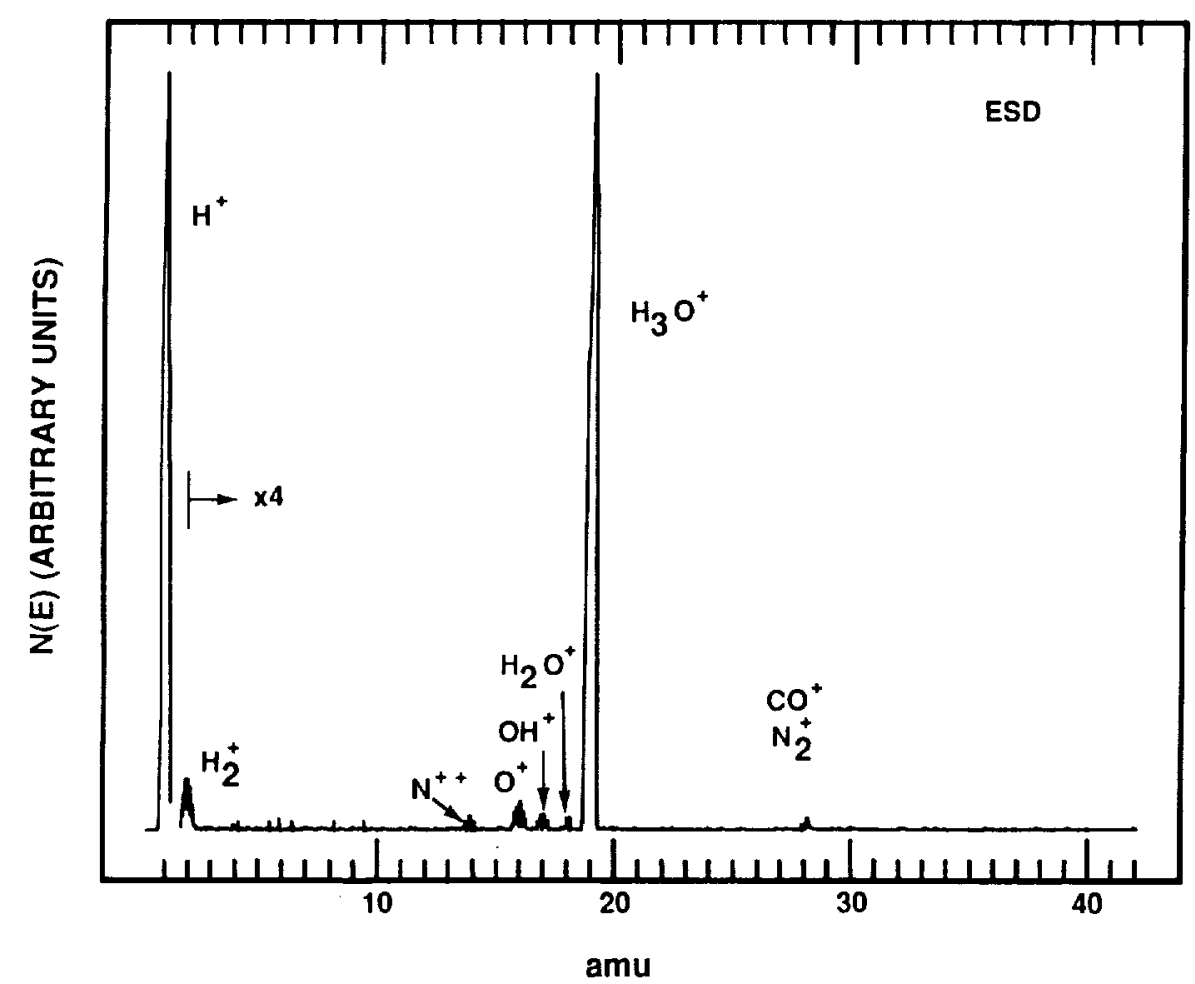

Figure 11. $\mathrm{m} / \mathrm{e}$ ESD spectrum taken from the $100^{\circ} \mathrm{C}$-reduced tin oxide surface. 


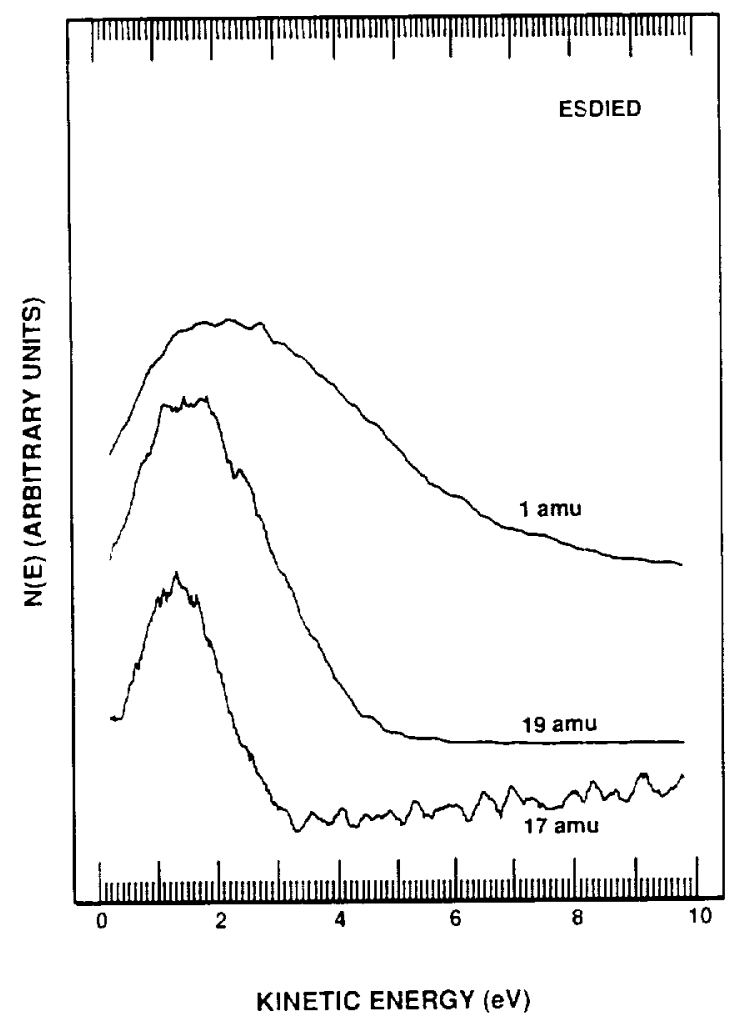

Figure 12. ESDIED spectra taken from the $100^{\circ} \mathrm{C}$-reduced tin oxide surface.

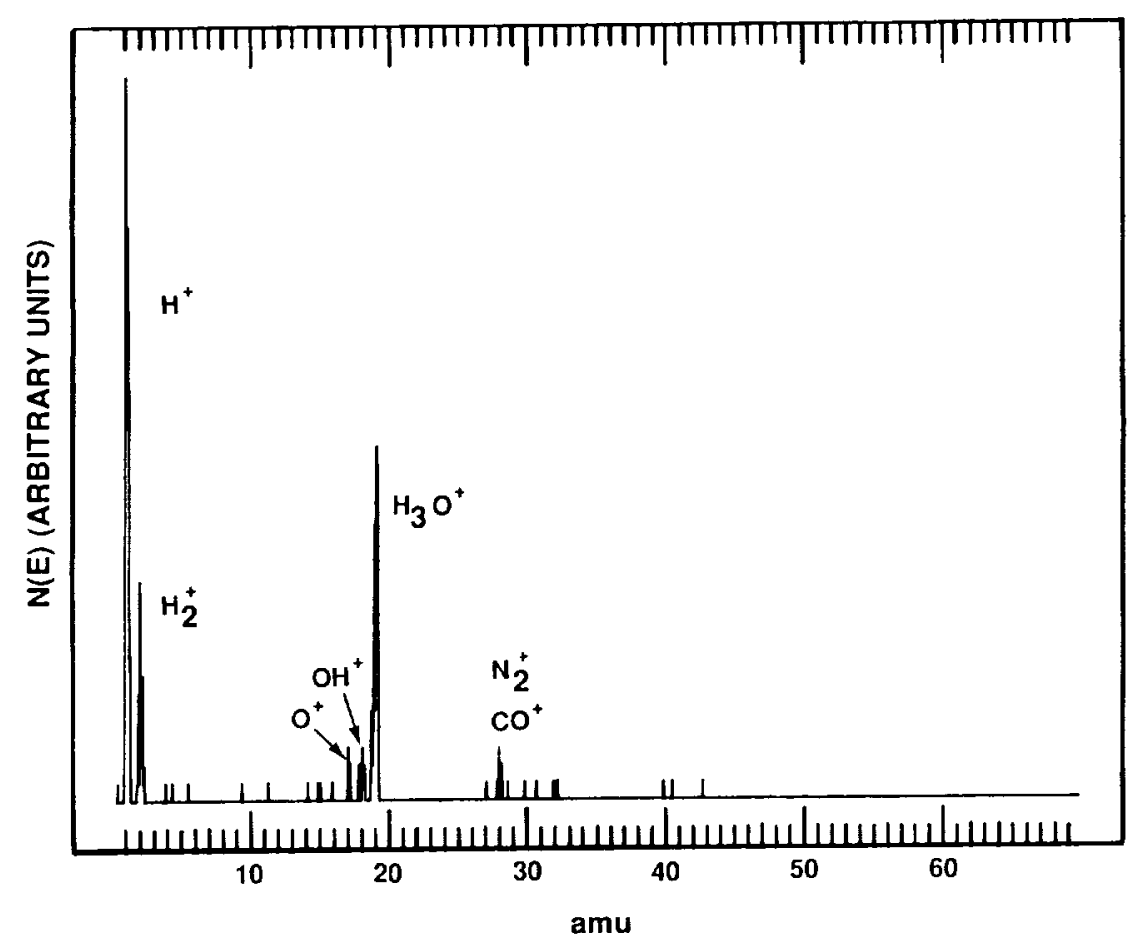

Figure 13. m/e ESD spectrum taken from the $175^{\circ} \mathrm{C}$-reduced tin oxide surface. 


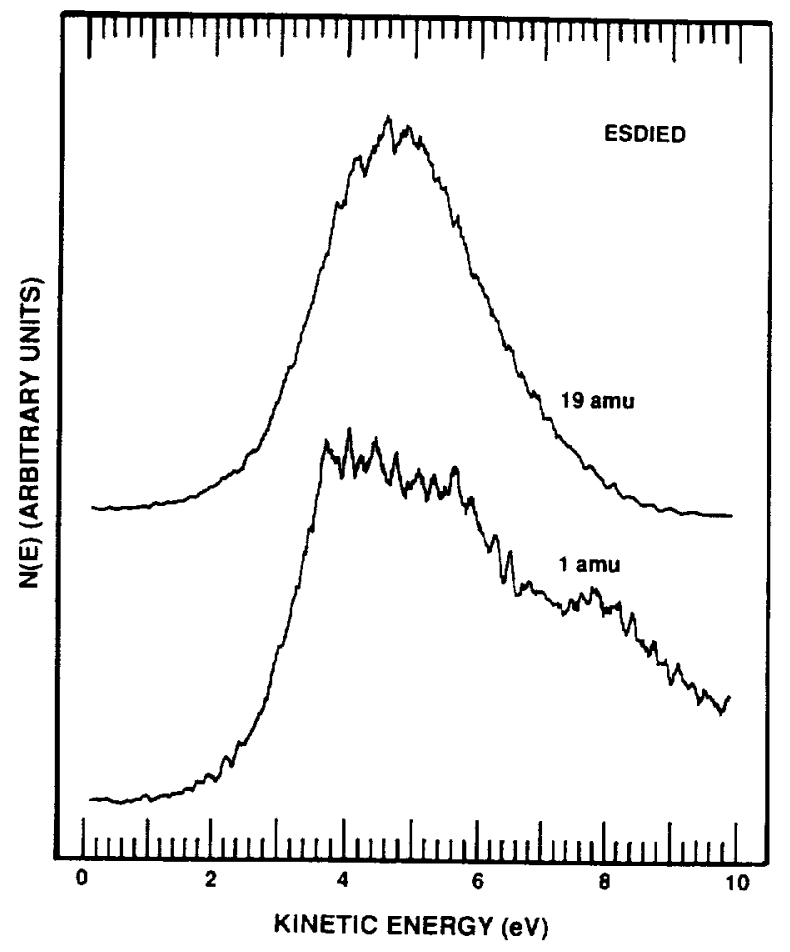

Figure 14. ESDIED spectra taken from the $175^{\circ} \mathrm{C}$-reduced tin oxide surface. 